\title{
Diversity and ecological structure of vibrios in benthic and pelagic habitats along a latitudinal gradient in the Southwest Atlantic Ocean
}

Luciane Chimetto Tonon, Bruno Sergio Silva, Ana Paula Moreira, Cecilia V P Pereira, Nelson Alves Junior, Giselle Cavalcanti, Gizele D. Garcia, Rubens Lopes, Cristiane Thompson, Fabiano Thompson

We analyzed the diversity and population structure of the 775 Vibrio isolates from different locations of the southwestern Atlantic Ocean (SAO), including St. Peter and St. Paul Archipelago (SPSPA), Abrolhos Bank (AB) and St. Sebastian region (SS), between 2005 and 2010. In this study, 195 novel isolates, obtained from seawater and major benthic organisms (rhodoliths and corals), were compared with a collection of 580 isolates previously characterized (available at www.taxvibrio.Incc.br). The isolates were distributed in 8 major habitat spectra according to AdaptML analysis on the basis of pyrH phylogenetic reconstruction and ecological information, such as isolation source (i.e. corals: Madracis decactis, Mussismilia braziliensis, M. hispida, Phyllogorgia dilatata, Scolymia wellsi; zoanthids: Palythoa caribaeorum, P. variabilis and Zoanthus solanderi; fireworm: Hermodice carunculata; rhodolith; water and sediment) and sampling site regions (SPSPA, $A B$ and $S S)$. Ecologically distinct groups were discerned through AdaptML, which finds phylogenetic groups that are significantly different in their spectra of habitat preferences. Some habitat spectra suggested ecological specialization, with habitat spectra 2, 3, and 4 corresponding to specialization on SPSPA, $A B$, and SS, respectively. This match between habitat and location may reflect a minor exchange of Vibrio populations between geographically isolated benthic systems. Moreover, we found several widespread Vibrio species predominantly from water column, and different populations of a single Vibrio species from $H$. carunculata in ecologically distinct groups ( $\mathrm{H}-1$ and $\mathrm{H}-8$ respectively). On the other hand, AdaptML detected phylogenetic groups that are found in both the benthos and in open water. The ecological grouping observed suggests dispersal and connectivity between the benthic and pelagic systems in AB. This study is a first attempt to characterize the biogeographic distribution of vibrios in both seawater and several benthic hosts in the SAO. The benthopelagic coupling observed here stands out the importance of vibrios in the global ocean health. 
1 Luciane A. Chimetto Tonon ${ }^{1,2}$, Bruno Sergio de O. Silva ${ }^{1}$, Ana Paula B. Moreira ${ }^{1}$, Cecilia

2 Valle ${ }^{1}$, Nelson Alves $\mathrm{Jr}^{1}$, Giselle Cavalcanti ${ }^{1}$, Gizele Garcia ${ }^{1}$, Rubens M. Lopes ${ }^{3}$,

3 Cristiane C. Thompson ${ }^{1}$, Fabiano L. Thompson ${ }^{1 *}$

$4{ }^{1}$ Laboratory of Microbiology, Institute of Biology. Federal University of Rio de Janeiro

5 (UFRJ), Rio de Janeiro, Brazil. ${ }^{2}$ Brazilian Biosciences National Laboratory (LNBio).

6 National research center energy and materials (CNPEM). Campinas, Brazil ${ }^{3}$ Institute of

7 Oceanography, University of São Paulo (IO-USP), São Paulo, Brazil.

8 Running headline: Vibrios in the Southwestern Atlantic Ocean

$9{ }^{*}$ Corresponding author: Address: Av. Carlos Chagas Fo. S/N - CCS - IB - BIOMAR -

10 Laboratório de Microbiologia - Bloco A (Anexo) A3 - sl 102 - Cidade Universitária, Rio

11 de Janeiro - RJ, Brasil. CEP 21941-599. Telephone/fax: 5521 2562-6567; Email:

12 fabiano.thompson@biologia.ufrj.br

13 Subjects: Marine Biology, Biodiversity, Ecology, Microbiology

14 Keywords: Vibrio, habitats, corals, rhodoliths, benthos, plankton, AdaptML

15 Introduction

16 The microorganisms' distribution in space does not occur evenly, but generally, it is 17 efficiently because local environmental conditions selects specific populations to 18 become relatively more abundant. In situations where this may be a good approximation 
19 of the primary mechanisms creating population structure, one can invoke a niche theory

20 to understand how organisms interact with other species and their environment (Tilman,

21 1982). Under this model, competition with co-existing organisms is an important

22 determinant of which species are present in specific environment (Hibbing et al., 2010).

23 Over evolutionary time scales, competition can cause species to adapt alternative life-

24 styles, e.g. to attach to different hosts or different substrates in the same hosts. Such

25 trade-offs are a necessary result of constraints on cellular machinery, such as cell26 surface proteins and enzymatic capacity or genome size, resulting in specialized

27 populations with limited niche overlap (Preheim, 2010).

28 Microbes associated with benthic holobionts, such as corals, play key roles in the health 29 of their hosts (Rosenberg et al., 2007). Vibrios represent a significant component of the 30 culturable microbiomes of marine hosts and plankton. Their proliferation and population 31 abundance can be induced by multiple factors including increased water temperature 32 related to global climate change, which can cause impacts in ecosystem structure, 33 including Vibrio-associated diseases (Baker-Austin et al. 2012, Vezzulli et al. 2012). 34 However, when vibrios' proliferation is not favored, they are able to find refuge in 35 suitable reservoirs to survive, making use of their extensive adaptive capabilities. For 36 instance, vibrios can change from free-swimming cells to "swarmer cells" that prosper in 37 more viscous environments such as biofilms (McCarter 1999), or switch from an active 38 stage to a dormant, viable but not culturable (VBNC) stage, but yet may still be very 39 potent opportunists if favorable conditions recur (McDougald \& Kjelleberg 2006).

40 Previous studies suggest that the proliferation of vibrios in the plankton results in lethal 41 vibrio infections in the benthos, suggesting mechanisms of benthopelagic coupling. In 
42 other words, these events reveal a causal relationship between water-column and

43 benthic processes, which may influence the health of global ocean (Vezzulli et al, 2010;

44 2012). For instance, an increase in seawater temperature (average range $21.0^{\circ} \mathrm{C}$ to

$4524.3^{\circ} \mathrm{C}$ ) appears to induce the growth of certain vibrios (e.g. V. harveyi related species)

46 and the concomitant mass mortality of the gastropod Haliotis discus hannai in northern

47 Japan (Fukui et al., 2010). It has also been shown that the ocean warming observed in

48 the last decades has induced a significant increase in the abundance and range of

49 vibrios in a long-term study in the North Sea (Vezzulli et al., 2012). Moreover, increases

50 of organic material used by Vibrio for energy may be additional factor in determining

51 Vibrio dynamics. Phosphorous, for example, seems to influence the abundance of

52 planktonic vibrios according to a metagenomic study of bacterioplankton diversity in a

53 tropical bay. According to this study, nutrient limitation effects can be observed at

54 community (metagenomic) and population levels (total prokaryote and vibrio counts)

55 (Gregoracci et al., 2012). Vibrios display broad metabolic ranges and enzyme activities

56 that enable them to use a wide variety of carbon sources (Thompson \& Polz 2006).

57 Nevertheless, it is not clear whether vibrioplanktonic cells are genetically and

58 ecologically coupled to vibrio cells that live in association with holobionts.

60 We previously reported massive mortality of the major coral reef builder, Mussismilia

61 braziliensis, and we isolated potential causative agents (Francini-Fo. et al., 2008; Alves

62 et al., 2010). According to these former studies, the diseases affecting corals were tissue

63 necrosis in Phyllogorgia dillatata, bleaching in M. hispida and white plague and

64 bleaching in M. braziliensis. Most of the isolated vibrios fell into the Harveyi clade

65 (Sawabe et al., 2007, 2013) and V. coralliilyticus. The vibrio isolates of these studies

66 encompassed strains originating from both apparently healthy and diseased corals and 
67 had high pathogenic potential for different animals. V. alginolyticus $40 \mathrm{~B}, V$. communis

68 1DA3 and $V$. coralliilyticus 2DA3 caused $25-88 \%$ mortality in the model organism

69 Drosophila melanogaster (Alves et al., 2010). However, the possible ecologic structure

70 and genetic connectivity among vibrios from the coastal-oceanic and benthic-pelagic

71 systems of the SAO remains unclear.

72 Studies performed in subtropical areas indicate that coastal vibrioplanktonic

73 communities are finely structured in discrete phylogenetic clusters, revealing the co-

74 occurrence of several hundreds of closely related populations (Thompson et al., 2005).

75 Sympatric differentiation may be due to niche partitioning and specialization, with the

76 association of different groups of bacterioplanktonic species with different habitats

77 (zooplankton, particles and water) in the same geographic location. Hunt et al. (2008)

78 showed that some vibrio species appeared to occur only in association with plankton,

79 whereas other species appeared to be exclusively free-living.

80 Little is known about the vibrioplankton population diversity and structure in the SAO,

81 and whether vibrioplankton diversity is linked to benthic compartments in this region.

82 Oceanic islands, and reef systems, such as Saint Peter and Saint Paul Archipelago

83 (SPSPA) and Abrolhos Bank (AB) are important environments located in the SAO.

84 SPSPA is constituted by five emerged summits of the Mid-Atlantic Ridge approximately

$851000 \mathrm{~km}$ off the coast of Natal (Moreira et al., 2013). It is a biodiversity hotspot. AB is an

86 extension of the continental shelf off the south of the Brazilian State Bahia (17-20 S),

87 corresponding to approximately $45,000 \mathrm{~km}^{2}$ (Amado-Filho et al., 2012). This bank 88 comprises the world's largest rhodolith bed (aggregates of non-geniculate crustose 89 coralline algae nodules) forming large expanses of hard bottom habitat with 
90 approximately $21,000 \mathrm{~km}^{2}$, contributing to the SAO as a nursery place, nutrient producer

91 and carbonate storage (Cavalcanti et al., 2013a; 2013b). Rhodolith beds stand

92 together with kelp beds, seagrass meadows, and crustose coralline algae

93 reefs as one of the world's four largest macrophyte-dominated benthic

94 communities (Foster 2001). AB is a particularly nutrient rich reef system, with higher

95 nutrients concentration levels than reef systems less influenced by river estuaries (Bruce

96 et al., 2012). SPSPA and $A B$ are under the influence of water masses formed by the

97 warm and salty Tropical Water (TW), with temperature values ranging from 22 to $27^{\circ} \mathrm{C}$,

98 and salinity values ranging from 36.5 to 37 (Castro and Miranda, 1998; MMA, 2006).

99 The benthic communities occurring in the different islands may also be locally a source

100 of nutrients in the SAO. SS is a sea passage $25 \mathrm{~km}$ long, $2-7 \mathrm{~km}$ wide and $40 \mathrm{~m}$

101 maximum depth located between the island of São Sebastião (municipality of Ilhabela)

102 and the mainland (São Sebastião), on the coast upstate São Paulo, southeastern Brazil.

103 The currents in the channel are directed by the wind and the water temperature range is

$10415-28^{\circ} \mathrm{C}$. The region is influenced by both the warm waters of the Brazil Current (22-

$\left.10528^{\circ} \mathrm{C}\right)$ that goes down to the south and, the cold $\left(<13^{\circ} \mathrm{C}\right)$ and saltier $(\sim 36 \mathrm{psu})$ South

106 Atlantic Central Waters (ACAS (Oliveira \& Marques, 2007).

107 Based on analysis of the diversity and population structure of vibrios, by using a 108 collection of new isolates originated from seawater, sediment, rhodoliths, coral 109 (Scolymia welsii), and previously characterized strains (Chimetto et al., 2009; Alves et 110 al., 2010; Moreira et al., 2013) from different environments located in the SAO, we

111 investigated (i) the habitat spectra of Vibrio populations in the SAO; (ii) whether these

112 vibrio population were generalist- and/or specialist-adapted; and (iii) if there was

113 connectivity among the benthic-pelagic systems in $A B$, the largest South Atlantic 
114 reef complex. We performed the taxonomic characterization of the isolates using the

115 reliable taxonomic marker gene $\mathrm{pyrH}$ (which has higher discriminatory power than $16 \mathrm{~S}$

116 rRNA sequences, allowing the distinction of closely related Vibrio species) (Thompson et

117 al. 2005, 2007) and inferred ecological associations by using a mathematical model 118 (AdaptML) (David, 2010; Hunt et al., 2008).

\section{Material and Methods}

\section{Sources of Isolation}

121 In total, 775 vibrio strains, isolated between 2005 and 2010, and identified by means of

$122 \mathrm{pyrH}$ sequences, were analyzed. Information on locations and sources are detailed in

123 Table S1 (strain list). The geographic span represents over $3,000 \mathrm{Km}$, including the 124 oceanic SPSPA, AB, and the southeastern Brazilian Saint Sebastian channel (SS)

125 (Figure 1, map). For the 195 novel isolates, sources were: sediments from the Buracas $126(\mathrm{~N}=25)$ (for a full description of the so called Buracas reef system see Cavalcanti et al., 127 2013a); rhodoliths ( $N=76)$ (for a full description of the rhodoliths holobiont see 128 Cavalcanti et al., 2013b) from 27 and 43m depth; seawater from AB, from 10 and $150 \mathrm{~m}$ 129 depth $(\mathrm{N}=76)$, including two locations (station 61: closer to shore, and station 65: 130 oceanic), and S. welsii mucus ( $\mathrm{N}=18)$, from SPSPA. The remainder 580 strains were 131 obtained previously (Chimetto et al., 2009; Alves et al., 2010; Moreira et al., 2013) and

132 isolated from: corals (Madracis decactis, Mussismilia braziliensis, M. hispida, 133 Phylogorgia dilatata); zoanthids (Palythoa caribaeorum, P. variabilis and Zoanthus 134 solanderi), and fireworm (Hermodice carunculata). These previously characterized data 135 contributed to increase the number of habitat categories under comparison as well as 136 their geographic extent, allowing a more comprehensive evaluation of potential 
137 ecological and genetic relationships among locations. Sampling permit Sisbio n. 24732-

1381 was issued by the Ministry of Environment Institute Chico Mendes (ICMBio).

139 Isolation and preservation of vibrios

140 Vibrios originating from the water column were obtained from inoculation, performed on

141 board the RV Prof. W. Besnard, in July 2007, in AB. Samples were collected with a 142 rosette system in three depths $(10,75$ and $150 \mathrm{~m})$ in station $65\left(17^{\circ} 0^{\prime} 36^{\prime \prime} \mathrm{S} ; 36^{\circ} 59^{\prime}\right.$ $14356.4^{\prime \prime} \mathrm{W}$-oceanic), and at $10 \mathrm{~m}$ in station $61\left(17^{\circ} 0^{\prime} 3.6^{\prime \prime} \mathrm{S}\right.$; $39^{\circ} 0^{\prime} 0^{\prime \prime} \mathrm{W}$ - on the shelf).

144 Samples from sequential filtration $(200 \mathrm{~mL})$ in $3 \mu \mathrm{m}$ and $0.22 \mu \mathrm{m}$ filters and aliquots of 145 unfiltered seawater $(1 \mathrm{~mL})$ were plated onto the culture medium thiosulfate-citrate-bile 146 salt-sucrose Agar (TCBS) (Oxoid) to obtain vibrios strains. Plates were incubated at 26 -

$14728^{\circ} \mathrm{C}$ for $48-72 \mathrm{~h}$. Similarly, in independent cruises to SPSPA $\left(00^{\circ} 56^{\prime} \mathrm{N} ; 2^{\circ} 22^{\prime} \mathrm{W}\right)$ and 148 the Buracas reefs (27m deep: $17^{\circ} 81^{\prime} 33.0^{\prime \prime} \mathrm{S} ; 38^{\circ} 23^{\prime} 74.4^{\prime \prime} \mathrm{W}$ and $43 \mathrm{~m}$ deep: $17^{\circ} 81^{\prime}$ $14939.9^{\prime \prime}$ S; $38^{\circ} 24^{\prime} 30.6^{\prime \prime} \mathrm{W}$ ) in 2010 , aliquots of coral mucus (S. welsii,) and rhodoliths 150 were surveyed. Rodoliths were crushed and homogenized $(0.1 \mathrm{~g})$ in sterile saline buffer $151(3 \% \mathrm{NaCl}, \mathrm{SSB})$. Coral mucus was 10-fold serially diluted in SSB. Homogenates (0.1 $152 \mathrm{~mL}$ ) were plated in triplicates in TCBS at $28 \mathrm{C}^{\circ}$. Isolates were purified at Federal 153 University of Rio de Janeiro (UFRJ). The pure cultures were maintained in vials with 154 Tryptic Soy Broth (Oxoid) with 3\% NaCl or Marine Broth media, both supplied with 20\% 155 (v/v) glycerol, and preserved at $-80^{\circ} \mathrm{C}$.

\section{Taxonomic characterization}

157 Characterization of all vibrio isolates was obtained by pyrH sequencing ( $80 \mathrm{~F}$ and $530 \mathrm{R}$ 158 primers) as described previously (Thompson et al., 2005). DNA extraction was 
159 performed based on Pitcher et al. (1989). PCR sequencing reactions, consensus

160 sequences determination and alignment were performed as in Moreira et al. (2013).

161 Phylogenetic trees were built in MEGA 5 (Tamura et al., 2011). The topology of the tree

162 was based on neighbor-joining method. Distance estimations were obtained according

163 to Kimura-2-parameter and Maximum Composite Likelihood model. Bootstrap

164 percentages were used after 1000 replications. To analyze the ecological grouping

165 multifasta file was converted in MEGA 5 to PHYLIP 3.0 format. The .phy file was used as

166 input to PhyML 2.44 (Guindon and Gascuel, 2003; Guindon et al., 2010) where the

167 suitable tree was generated and again used as input file for the AdaptML software

168 (David, 2010; Hunt et al., 2008). Tree figures were generated using the interactive Tree

169 of Life web application (itol.embl.de) (Letunick and Bork, 2007).

170 Ecologic grouping of vibrios

171 Clusters of vibrios' sequences were obtained with the software AdaptML as described

172 previously (David, 2010; Hunt et al., 2008). In brief, the software combines genetic

173 information embedded in sequence-based phylogenies and information about the

174 ecology, herein source and place of isolation, in order to identify genetically- and

175 ecologically-distinct bacterial populations. This quantitative model (AdaptML) uses a

176 Hidden Markov Model to predict the phylogenetic bounds of ecologically distinct

177 populations, and their habitat composition (distribution among environmental

178 categories). AdaptML algorithm can account for environmental parameter discretization

179 schemes and is based on the model concept of a habitat (a place and related features

180 that determines microbial distribution). Habitats are characterized by discrete probability

181 distributions describing the likelihood that a strain adapted to a habitat will be sampled

182 from a given ecological state (e.g. at a particular location in the water column or in a 
183 specific host). Habitats are not defined a priori but rather learned directly from the

184 sequence phylogeny and ecological data using an Expectation Maximization routine.

185 Once habitats are defined, a maximum likelihood model is used for the evolution of

186 habitat association on the tree (David, 2010; Hunt et al., 2008). The habitat-learning and

187 clustering steps of AdaptML were performed using the default settings. Confident

188 assignments are show for ecological populations predicted by the model. The model

189 threshold value was set at 0.05 and Photobacterium was used as out-group. The

190 Bootstrap percentages analysis was rerun 100 times with the same phylogenetic tree to

191 verify the stability of the predictions. Circular tree figure was drawn using the online ITOL

192 software (Letunick and Bork, 2007). To prevent numerical instabilities in AdaptML's

193 maximum likelihood computations, branches with zero length were assigned the minimal

194 observed non-zero branch length: 0.001 . Clades supported in $80 \%$ of bootstraps were

195 shown. The visualization of the distribution of Vibrio groups in all habitats (Fig. S2) was

196 generated by the online tool Many Eyes (IBM Many Eyes Project; Viégas et al., 2007).

197 All gene sequences obtained in this study are available through the website TAXVIBRIO

198 (http://www.taxvibrio.Incc.br/). The GenBank accession numbers for the pyrH sequences 199 reported in this study are KC871632 - 720; KJ154031 - 48; EU251514 - 1689; 200 EU716656 - 7075; GU186166 - 6371; KC871598 - 1720.

\section{Results}

202 Taxonomic assignment of the vibrio isolates

203 The taxonomic characterization of the isolates was mainly based on the phylogenetic 204 position of $\mathrm{pyrH}$ gene sequences and its similarities in relation to the closest type strain 
205 of Vibrio species. The $\mathrm{pyrH}$ gene has shown to be a reliable taxonomic marker for the

206 Vibrio group, even able to discriminate closely related species. (Thompson et al. 2005,

207 2007).However, in some cases we also performed a Multilocus sequence Analysis

208 (MLSA) of housekeeping genes and whole genome sequence (Chimetto et al., 2009,

209 Moreira et al., 2014). Most of the vibrio isolates were V. communis (21.9\%), V.

210 mediterraneilV. shiloi (19.7\%), V. harveyi (12.4\%), V. alginolyticus (9.5\%), V. campbellii

211 (7.7\%). Other prevailing groups were V. maritimus (4.5\%), V. tubiashii (3.5\%), V.

212 coralliilyticus (3.1\%), V. pelagius (2.5\%), V. diabolicus (2.2\%) and V. chagasii (1.8\%). In

213 addition, 22 strains (2.8\%) were identified as candidate new Vibrio species based on

214 16S rRNA (data not shown) and pyrH gene sequence similarities. Ecological populations

215 predicted by the AdaptML model totalized 19 Vibrio groups clustered accordingly Fig. 2.

216 Most species found in the water column (i.e. V. communis, V. campbellii, V. harveyi, V.

217 maritimus, $V$. pelagius and $V$. diabolicus) were also isolated from different invertebrate

218 hosts (Table 1 and S1). However, some species as V. hepatarius and a unique strain of

219 V. alfacsensis were found only in water samples, whilst $V$. rotiferianus only in the

220 benthos, coral and zoanthid samples (M. hispida, M. braziliensis, $P$. dilatata and $P$.

221 caribaeorum). Some species were retrieved from a single given host. V. sinaloensis was

222 found only in the coral Mussismilia (hispida and M. braziliensis), as well as V. fortis was

223 associated only with M. hispida. V. shiloi was found mainly in association with the

224 fireworm $H$. carunculata and also with M. hispida in SS. V. furnissii was only associated

225 with $H$. carunculata. We observed low counts (colony forming units - CFU) in the water

226 column (typically $<10^{2}$ per $\mathrm{mL}$ ) compared with the abundance of vibrios in reef waters

227 (up to $10^{4} \mathrm{CFU} \mathrm{mL} \mathrm{m}^{-1}$ ) (Bruce et al., 2012) and in the coral mucus $\left(10^{6} \mathrm{CFU} \mathrm{mL}{ }^{-1}\right)$ (Alves 228 et al., 2010; Moreira et al., 2013). 


\section{PeerJ Reviewing Manuscript}

229 Partitioning of vibrio isolates according to their genetic and ecological similarity

230 The Vibrio isolates were distributed in 8 habitat spectra. Herein habitat is a spectrum of

231 environment types over which a given population may be isolated from (Table S2; Figure

2322 and S1). The three studied areas (i.e. SPSPA, AB and SS) and their distribution in the

233 composition of each habitat spectrum is shown in Figure S1. Some spectrum of habitat

234 were mainly composed by categories from an unique geographic region as in habitats 1

235 and $3(\mathrm{H}-1, \mathrm{H}-3)$ (from $\mathrm{AB})$, habitats 2 and $8(\mathrm{H}-2, \mathrm{H}-8)$ (from SPSPA) and habitat $4(\mathrm{H}-$

236 4) (from SS). Although habitats 5,6 and $7(\mathrm{H}-5, \mathrm{H}-6, \mathrm{H}-7)$ seemed to be more variable,

237 geographic predominance was observed for $\mathrm{H}-6$, dominated by categories from $A B$ 238 (67\%), followed by those from SPSPA (25\%) and SS (8\%) (Fig. S1). H-1 was mainly

239 composed of strains isolated from water (86\%), H-2 from M. decactis (92\%), H-3 from

240 M. braziliensis (72\%), H-4 from M. hispida (69\%), H-5 from Mussismilia (hispida and

241 brasiliensis) (72\%), H-6 from rhodolith (44\%), H-7 from P. caribaeorum (50\%) and $\mathrm{H}-8$

242 from H. carunculata (94\%) (Figure3).

243 Although the observation of these different microenvironments in SAO was based on

244 single sampling the correlation found among the inferred habitat spectra, sampling sites,

245 isolation sources and the associations with all ancestors of the vibrios studied indicated

246 structured populations (Figure 2). The predominant environmental category in the

247 composition of each predicted habitat spectrum can be clearly visualized in Figure 3.

248 In more detail, $\mathrm{H}-1$ was characterized mostly by vibrios from $\mathrm{AB}$ seawater (86\%) and it

249 was divided into 7 groups occupied by different Vibrio species (Fig. 2 marked with 250 asterisk, and Table S2). V. pelagius (group 1); V. maritimus (groups 2 and 3); V.

251 hepatarius (group 4), and V. communis, V. campbellii and V. diabolicus (groups 5-7). H-2 
252 was composed mostly of isolates from $M$. decactis - SPSPA (92\%) and from $A B$ 253 seawater $(5 \%)$, V. campbellii $(\mathrm{N}=42)$, candidate Vibrio sp. nov $(\mathrm{N}=19)$ and $V$. maritimus $254(\mathrm{~N}=15)$ were the most frequently found species (Fig. S3 and Table S2). Two clusters of

255 V. maritimus, one from AB seawater and the other from SPSPA M. decactis, were clearly 256 distinguished (Fig. S3). H-6 had mainly (57\%) vibrios from Buracas - AB (44\%: rhodolith, 257 13\%: sediment) and from seawater (6\%) (Fig. S3). Species highlighted were V. harveyi, 258 V. communis, V. coralliilyticus, V. tubiashii and candidate Vibrio sp. nov. (Figure S2). H-7 259 was mainly represented by the same Vibrio species found in $\mathrm{H}-6$, except for potencial 260 new Vibrio species and the presence of $V$. rotiferianus. The hosts observed in this 261 habitat were P. caribaeorum (50\%) and M. hispida (12\%) both from SS; P. dilatata (23\%:

262 Recife de Fora), M. braziliensis (10\%: Saint Barbara Island), rhodoliths (3\%: Buracas), 263 and water (2\%: AB) (Fig. 3 and Table S2).

264 H-3 encompassed mostly isolates associated with Mussismilia (78\%), mainly $M$. 265 braziliensis $(68 \%)$ (Roi-Roi reef $-\mathrm{AB}$ ). The species adapted to this habitat spectrum 266 were V. coralliilyticus, V. harveyi, V. communis, V. sinaloensis and V. tubiashii (Figure 267 S3). H-4 was mostly represented by benthic animals from SS channel (85\%). The main 268 host (72.5\%) was M. hispida (69\%: SS, $2 \%$ : AB) .M. braziliensis was also represented 269 (1.5\%: $A B$ ). Vibrio species observed in $\mathrm{H}-4$ were $V$. alginolyticus, $V$. communis, $V$. 270 campbellii, V. tubiashii, V. chagasii and V. sinaloensis (Fig. S2). H-5 was composed of 271 environmental categories from $A B(61 \%)$ and SS (37\%) (Fig. 3 and Table S2). The 272 dominant category was the host Mussismilia (72\%), including both species: M. hispida 273 (46\%: AB and SS) and M. braziliensis (26\%: AB). V. communis and V. alginolyticus were 274 the dominant species (Fig. S2). H-8 comprised mostly V. shiloi associated with $H$. 


\section{PeerJ Reviewing Manuscript}

275 carunculata in SPSPA (94\%) A few V. shiloi strains were associated with M. hispida in 276 SS (6\%) (Fig. 3).

277 Connectivity among the benthic-pelagic systems in Abrolhos bank.

278 The presence of identical $p y r H$ sequences of vibrios from planktonic and coral reinforce

279 the hypothesis of connectivity (Fig.S3). For instance V. communis (PEL4D from 150m 280 depth and R-680 from M. hispida, G35, G52 from rhodoliths), (PEL103A from 10m depth 281 and R-239, R-264 from M. hispida); V. harveyi (PEL36B from 10m depth and 1DA5 from 282 P. dilatata); V. campbellii (PEL44A from 10m depth and 42A from M. hispida, PEL45A 283 from 10m deep and A-391 from M. decactis); V. diabolicus (PEL41D from 150m depth 284 and 4D2 from $P$. dilatata); $V$. pelagius (PEL22B from 10m depth and 28A2 from $M$. 285 hispida) and $V$. chagasii (PEL47A from 75m depth and PA10 from M. braziliensis and 286 1DA1 from P. dilatata) (Figure S3). Samples from water clustered with samples from 287 benthos are hhighlights $\left(^{*}\right)$ in Figure 2.

288 On the other hand, some clusters of planktonic strains seemed to have unique pyrH 289 gene sequences (i.e. V. maritimus group, PEL21 (A, B, C, E and F - station 61,10 m); 290 PEL102 (A e B), PEL106A, PEL111A, PEL121C, PEL122A, PEL124A and PEL125 (A 291 and B); and V. pelagius group PEL115 (A, B, C, D, E, F, G, H and J - station 65, 150m) 292 (Figure S3). The distribution pattern of the main Vibrio species from benthic and pelagic 293 sources in $A B$ based on evolutionary history inferred by using the Neighbor-Joining 294 method of $p y r H$ gene sequence (532 positions) can be visualized in the Fig.S4 
295 A more targeted AdaptML analysis was performed by dividing the isolation sources in 296 generic hosts from benthic and pelagic, to explore the extent and significance of the 297 coupling events. It resulted in a very similar cluster distribution of the populations of 298 vibrios. . Again, isolates from Abrolhos Bank, both from open water and benthos, were 299 present in the same branches. However, the number of habitat spectra stablished were 300 reduced to six (H1-H6). (Fig.S5).

301 Discussion

302 Vibrio population distribution in the Southeastern Atlantic

303 The predicted habitats spectrum were dispersed along a spatial gradient ca. 3,000 km, 304 from the coastal southeastern SS to the most distant from coast Brazilian archipelago, 305 located above the Equator (SPSPA). Ecologically coherent groups were associated with 306 seawater $(\mathrm{H}-1)$, corals $[M$. decactis $(\mathrm{H}-2)$, M. braziliensis $(\mathrm{H}-3)$, M. hispida from SS $(\mathrm{H}-$ 307 4), both Mussismilia species (M. braziliensis and M. hispida) (H-5)], rodoliths and 308 sediment $(\mathrm{H}-6)$, zoanthids - P. dilatata and P. caribaeorum $(\mathrm{H}-7)$, and the polichaete $H$. 309 carunculata $(\mathrm{H}-8)$.

310 Vibrios' behavior showed a wide spectrum, from approaching a true generalist to a strict 311 specialist. The dominant group - the Communis cluster, was present in all habitats 312 spectrum, except for H-8 (mainly composed by the host fireworm), and in 10 out of the 31312 samples analyzed. This suggests that these hosts may serve as a reservoir for $V$. 314 communis' populations when their abundance in seawater decreases. The exceptions 315 were the zoanthid ( $Z$. solanderi) and the fireworm $(H$. carunculata). Nevertheless it's 316 worth to note that only $V$. alginolyticus inhabited $Z$. solanderi, according to this study, 
317 thus raising the possibility that antagonists among its populations (or the animal itself)

318 could be effective against vibrios. Apart the exceptions, V. communis' populations

319 showed a true generalist behavior. $V$. communis strains were isolated from multiple

320 independent samples and thus do not represent clonal expansion, suggesting that this

321 may reflect a true habitat switch. Moreover, V. communis appeared to have ecologically

322 diversified, possibly by invading new niches or partitioning resources at increasingly fine

323 scales in a similar way to $V$. splendidus in the northwestern Atlantic coast (Preheim et

324 al., 2011, Hunt et al., 2008). Despite recognized as a generalist, V. splendidus was not

325 represented in this study, what might reflect its low tolerance to high temperatures $(>21$

$326{ }^{\circ} \mathrm{C}$ ) (Materna et al., 2012). The other host that seemed unavailable to $V$. communis was

327 the fireworm in SPSPA. Contrasting to the high diversity that corals harbored, this host

328 was dominated by V. shiloi $(n=143)$ and some $V$. furnissii strains $(n=4)$. V. shiloi was also

329 present in corals (M. hispida) in SS. SPSPA and SS are the extremes of the latitudinal

330 gradient uncovered. Corals and the fireworm appear to define the habitat spectrum for

331 V. shiloi. Both host associations were previously observed in the Eastern Mediterranean

332 (Sussman et al., 2003), suggesting they are stable and that population-habitat linkage is

333 highly predictable for $V$. shiloi. Moreover, in this survey we found $V$. shiloi associated

334 with corals, in a human impacted coastal area (SS), and with fireworms in the oceanic 335 SPSPA.

336 Populations of vibrios in the SAO and those in the northwestern Atlantic showed narrow

337 intersection. In addition to $V$. splendidus, other vibrios found in the American northern

338 coast were V. rumoiensis, V. alginolyticus, V. fischerillogei, V. penaeicida, V. superstes,

339 V. aestuarianus, V. ordalii, V. breoganii, V. crassostreae, V. kanaloae, V. tasmaniensis,

340 V. gigantis, and V. cyclitrophicus (Preheim et al., 2011; Hunt et al., 2008). The only 
341 common group is $V$. alginolyticus. It was associated with zooplankton and also displayed

342 free-living style in the coastal northern hemisphere (Hunt et al., 2008). In this study V.

343 alginolyticus was also found in coatal areas of $A B$ and SS, but associated with almost all

344 cnidarians surveyed, and not in the seawater. Variation in host association and life style

345 may reflect genome heterogeneity, possibly due to a large set of flexible genes. In

346 members of the Vibrionaceae, small-scale differences in environmental

347 conditions based on microenvironment and season have been shown to drive

348 lineage adaptation (Hunt et al., 2008) and presumably genome content. A

349 representative study targeting $V$. alginolyticus genomes $(n=192)$ from the Chinese coast

350 revealed high prevalence of mobile genetic elements, including integrating conjugative

351 elements (ICEs), superintegron-like cassettes (SICs), insertion sequences (ISs), and two

352 types of transposase genes (valT1 and valT2). Moreover, BLAST searches and

353 phylogenetic analysis of the ICE, SIC, IS elements and transposase genes showed that

354 the corresponding homologues were bacterial derived from extensive sources, indicating

355 intensive exchange with environmental bacteria (Luo et al., 2012). Indeed, horizontal

356 gene transfer (HGT) mechanism has played an important role in bacterial evolution,

357 facilitating the origins of bacterial diversity and adaptation to new ecological niches

358 (Wiedenbeck and Cohan, 2011). An important feature shared by the habitats where $V$.

359 alginolyticus was common is the vicinity to coast, thus to human activities and nutrient 360 enrichment (SS, AB and Plum Island Estuary, NE Massachusetts).

361 When we look to the evolutionary history of the generalist and specialist vibrio 362 populations found in this study, two distinct clades defined by MLSA of 8 housekeeping 363 genes can be highlighted: Harveyi and Mediterranei respectively (Sawabe et al., 2007, 364 2013). Harveyi clade is composed by 9 species mainly associate with seawater, salt 
365 marsh mud, marine animal and mucus of the coral. In some cases, distinguishing

366 species and strains within this clade is hard task in taxonomy, because the presence of

367 recombination between closely related species. Meditteranei clade is composed by 4

368 species mainly found in habitats as warm seawater and coral mucus (Sawabe et al.,

369 2007, 2013; Moreira et al., 2014 - V. madracius sp novel). Although, the clades are not

370 phylogenetic very closely related, both possess typically pathogenic species in aquatic

371 environments (Reshef et al., 2008; Ruwandeepika et al., 2010; 2011).

372 We also observed geographic influence in $\mathrm{H}-4$, since it included $M$. hispida from SS, but

373 not from $A B$. H-5, 6,7 and 8 were mainly composed of benthic organisms from

374 combinations of two locations, revealing some connectivity across a spatial scale might

375 also occur. H-5 showed connectivity between $A B$ and SS. H-6 showed connectivity

376 between AB and SPSPA. H-7 showed connectivity between SS and SPSPA.

377 The influence of temporal dimension in habitat distribution is visualized in Fig.S6.

378 Although not all regions were sampled all years, there was prevalence of 2010 strains in

$379 \mathrm{H}-2, \mathrm{H}-6$ and $\mathrm{H}-8$; and of 2007 in $\mathrm{H}-1$ and $\mathrm{H}-3$. On the other hand, strains from 2005, 3802006,2007 and 2010 were present in $\mathrm{H}-4, \mathrm{H}-5$ and $\mathrm{H}-7$.

381 Habitat delineation and taxonomy are congruent

382 We observed a good congruence between the ecologic grouping generated by the 383 AdaptML and the currently recognized Vibrio species. However, the AdaptML provided 384 further refinement of the species into subspecific groups that may reflect niche 385 partitioning. For instance, we found groups of $V$. maritimus associated with the seawater 386 and with the coral M. decactis in SPSPA. We defined ecologic groups of vibrios that live 
387 in the water column and in association with the benthic organisms. Some species (such

388 as V. harveyi, V. aliynolyticus and V. communis) occupied different habitat spectra,

389 whereas other species (such as V. hepatarius, V. rotiferianus and V. brasiliensis)

390 appeared to be restricted to one habitat (Figure S2). Some habitat spectra (e.g. H-1) can

391 be defined by multiple species (e.g. V. communis, V. campbellii, V. diabolicus, V.

392 pelagius, $V$. hepatarius, V. maritimus and $V$. chagasii). These species are widespread in

393 the water column (up to $150 \mathrm{~m}$ depth), representing $86 \%$ of the isolates in this habitat 394 spectrum.

395 The ecological grouping observed in this study suggests dispersal and connectivity 396 among the benthic-pelagic systems in $A B$. The distribution pattern of the Vibrio species 397 from benthic and pelagic sources in $A B$ based on evolutionary history inferred by using 398 the Neighbor-Joining method of $\mathrm{pyrH}$ gene sequence (Fig.S4) corroborates with this 399 hypothesis. Genetic coherence among the strains from SS, SPSPA and AB also 400 contributes with the coupling idea. Conspecific identical isolates (e.g. PEL4D and R-680, 401 G35, G52; PEL 103A and R-239, R-264; PEL36B and 1DA5; and others), based on $402 \mathrm{pyrH}$ sequences, originated from the pelagic and benthic systems reinforced the idea of 403 connectivity. Even if AdaptML mistakenly have pooled open water specialists and 404 benthic specialists into one population, these identities (of $\mathrm{pyrH}$ sequences from benthic 405 and pelagic isolates) are strong evidence of benthopelagic coupling. It is noteworthy 406 identical $\mathrm{pyrH}$ sequences from both compartments and among distantly located isolates, 407 since this gene is one of the most divergent among the pool of housekeeping genes 408 employed for vibrios' MLSA (Thompson et al. 2005, 2007). Isolates from both open 409 water and benthic sites were also detected when the AdaptML analysis was based on 
410 generic hosts (benthic and pelagic). Moreover, similar cluster distribution of vibrios

411 populations were observed in both parameters analyzed (Fig. 2 and S5).

412 In spite of the low CFU counts observed in the water column, we suggest that dispersal 413 through the seawater may be important for the persistence of vibrios in the environment.

414 In reef waters, dispersal may be promoted by the shedding of bacteria by the coral host, 415 as a mechanism to regulate the abundance of associated bacteria (Garren \& Azam, 416 2012). The presence of both strategies in vibrios highlights their adaptation to thrive in

417 both oligotrophic (e.g. water column) and copiotrophic (e.g. coral mucus, organic matter 418 particles) environments, and illustrates the genome plasticity of this ubiquitous group.

419 Furthermore, several vibrios observed in the plankton of the $A B$ may have a pathogenic 420 potential to corals. However, we did not recover some known coral pathogens (e.g. V. 421 coralliilyticus and V. shiloi) in our pelagic survey, suggesting that some vibrio species 422 may have evolved into associated habitats, as the coral holobiont, for example, as 423 observed in the $\mathrm{H}-8$. It was demonstrated that $V$. shiloi and V. coralliilyticus use 424 chemotaxis to find their coral hosts, by sensing a $\beta$-D-galactopyranoside-containing 425 receptor and the metabolite dimethylsulfoniopropionate (DMSP), respectively, both 426 present in the coral mucus (Toren et al., 1998; Garren et al., 2013). V. coralliilyticus 427 employs also chemokinesis and its swimming ability is noteworthy (Winn et al., 2013; 428 Garren et al., 2013). These vibrios may thus have a higher host association frequency. 429 Interestingly, V. madracius retrieved only from the coral $M$. decactis, might indicate a 430 new ecological role of this bacterium in this host. This recently described species 431 (Moreira et al., 2014) is closed related to V. mediterranei/shiloi, known for the 432 pathogenicity. 


\section{PeerJ Reviewing Manuscript}

433 Influence of benthopelagic coupling in the coral reef health

434 We observed that several vibrios associated with the seawater and with benthic 435 organisms (corals) formed a cohesive ecologic unity, indicating the connectivity between

436 the benthic-pelagic compartments. Benthic communities obtain their energy through 437 primary production from the benthic compartment and, to a lesser extent, from the 438 overlying water column. Thereupon, the distribution and abundance of planktonic 439 microbes may be dependent on benthic processes, which affect the transfer of organic 440 material between benthic and pelagic systems (Fowler \& Knauer 1986). Bacteria and

441 phytoplankton production are also stimulated by resuspension of nutrients from the 442 seabed into the photic zone, which in turn stimulates zooplankton production, and so on 443 up the food chain (Wainright 1987). In the present study, we reinforce the power of 444 ecologic theory already developed for the study of vibrioplankton from temperate areas 445 (Materna et al., 2012; Szabo et al. 2013). The genetic connectivity observed among the 446 vibrios originated from the seawater and coral hosts in the SAO illustrates the potential 447 influence of the pelagic system in the coral reef systems health. In a scenario of 448 increasing abundance of vibrios, mediated by higher global oceanic temperatures, the 449 pathogenic potential of some Vibrio groups may lead to increased incidence of diseases 450 in the marine realm. For instance, V. vulnificus implicated in outbreaks were linked to 451 climate change in Israel (Paz et al., 2007), as well as V. parahaemolyticus outbreaks 452 documented in Alaska and linked to the consumption of raw seafood followed by 453 episodes of increased seawater temperature, pinpointing a link between climate change 454 and disease (McLaughlin et al 2005; Martinez-Urtaza et al., 2008).

\section{Conclusions}


456 This study was a first attempt to characterize the diversity and the ecological structure of

457 vibrios in several benthic hosts along a latitudinal gradient in the SAO. The occurrence

458 of vibrios from the benthic systems from SPSPA, AB, and SS in the habitats 2, 3 and 4,

459 respectively reinforces the hypothesis that each benthic system may have its own

460 microbiome. Moreover, V. communis' populations showed a true generalist behavior,

461 whilst $V$. shiloi was confirmed as specialist, associated to $H$. carunculata and corals.

462 AdaptML analysis generated a good congruence between ecologic grouping and the

463 currently recognized Vibrio species, with further refinement of the species reflecting

464 niche partitioning. Vibrios might occupy the pelagic and the holobiont habitats, indicating

465 coupling between these microbes and their benthic hosts. The benthic pelagic coupling

466 observed in $A B$, which is the largest South Atlantic reef complex, may suggest the

467 importance of vibrios in the global ocean health.

\section{Acknowledgements}

469 The authors thank Pedro Meirelles comments and technical support of Oswaldo Maia 470 and Milene MA Mesquita.

\section{Supplemental Information}

472 Supplemental information for this article can be found online

\section{Funding Statement}

474 The authors thank CNPq, FAPERJ, and CAPES for the grants.

\section{References}


1. Alves JrN, Neto OSM, Silva BSO, de Moura RL, Francini-Filho RB, Barreira e Castro C, Paranhos R, Bitner-MathÃ BC, Kruger RH, Vicente ACP, Thompson CC, Thompson FL. 2010. Diversity and pathogenic potential of vibrios isolated from Abrolhos Bank corals. Environmental Microbiology Reports 2:90-95. DOI: 10.1111/j.1758-2229.2009.00101.x

481

482

2. Amado-Filho GM, Moura RL, Bastos AC, Salgado LT, Sumida PY, Guth AZ, Francini-Filho RB, Pereira-Filho GH, Abrantes DP, Brasileiro PS, Bahia RG,

483

484 Leal RN, Kaufman L, Kleypas JA, Farina M, Thompson FL. 2012. Rhodolith beds are major $\mathrm{CaCO} 3$ bio-factories in the tropical South West Atlantic. PLoS One 7(4):e35171. DOI: 10.1371/journal.pone.0035171

486

3. Baker-Austin C, Trinanes JA, Taylor NGH, Hartnell R, Siitonen A, Martinez-

487

488 Urtaza J. 2013. Emerging Vibrio risk at high latitudes in response to ocean warming. Nature Climate Change 3:73-77. DOI: 10.1038/nclimate1628

489

490

4. Bruce T, Meirelles PM, Garcia G, Paranhos R, Rezende CE, de Moura RL, Filho RF, Coni EO, Vasconcelos AT, Amado Filho G, Hatay M, Schmieder R,

491

492

493

494

495

496

497 Edwards R, Dinsdale E, Thompson FL. 2012. Abrolhos Bank Reef Health Evaluated by Means of Water Quality, Microbial Diversity, Benthic Cover, and Fish Biomass Data. PLoS ONE 7(6): e36687. DOI:10.1371/journal.pone.0036687

5. Castro BM, Miranda LB. 1998. Physical oceanography of the western Atlantic continental shelf located between $4^{\circ} \mathrm{N}$ and $34^{\circ} \mathrm{S}$, in: Robinson, A.R., Brink, K.H. (Eds.), The Sea. 11, John Wiley and Sons, New York, pp. 209-252.

498

499

500

501

502

503

504

505

506

507

508

509

6. Cavalcanti G S, Gregoracci GB, Moura RL, Amado-Filho GM, Bastos AC, Francini-Filho R, Paranhos R, Ferreira, CM, Ghisolfi RD, Kruger R, Guth A. Z, Sumida PYG, Bruce T, Maia-Neto O, Santos EO, lida T, Thompson FL. 2013a. Sinkhole-like structures as bioproductivity hotspots in the Abrolhos Bank. Continental Shelf Research 70:126-134.DOI: 10.1016/j.bbr.2011.03.031

7. Cavalcanti GS, Gregoracci GB, Dos Santos EO, Silveira CB, Meirelles PM, Longo L, Gotoh K, Nakamura S, lida T, Sawabe T, Rezende CE, FranciniFilho RB, Moura RL, Amado-Filho GM, Thompson FL. 2013b. Physiologic and metagenomic attributes of the rhodoliths forming the largest $\mathrm{CaCO}(3)$ bed in the South Atlantic Ocean. ISME J 8(1):52-62. DOI: 10.1038/ismej.2013.133.

8. Chimetto LA, Brocchi M, Gondo ML, Thompson CC, Gomez-Gil B, Thompson FL. 2009. Genomic diversity of vibrios associated with the Brazilian coral Mussismilia hispida and its sympatric zoanthids (Palythoa caribaeorum, P. variabilis, and Zoanthus solanderi). Journal of Applied Microbiology 106: 18181826.DOI: 10.1111/j.1365-2672.2009.04149.x

512

513

514

515

516

517

518

9. David LA. 2010. Novel Phylogenetic Approaches to Problems in Microbial Genomics. Thesis. MIT. USA

10. Fowler SW, Knauer GA. 1986. Role of large sinking particles in the transport of elements and organic compounds through the water. Prog Oceanogr 16:147

11. Foster MS. 2001. Rhodoliths: between rocks and soft places. J Phycol 37: 659667. DOI: 10.1046/j.1529-8817.2001.00195.x

12. Francini-Filho RB, Moura RL, Thompson FL, Reis RM, Kaufman L, Kikuchi RK, Leão ZM. 2008. Diseases leading to accelerated decline of reef corals in the 

largest South Atlantic reef complex (Abrolhos Bank, eastern Brazil). Mar Pollut Bull 56(5): 1008-14. DOI: 10.1016/j.marpolbul.2008.02.013

522

523

524

525

526

527

528

529

530

531

532

533

534

535

536

537

538

539

540

541

542

543

544

545

546

547

548

549

550

551

552

553

554

555

556

557

558

559

560

561

562

13. Fukui Y, Saitoh S, Sawabe T. 2010. Environmental determinants correlated to Vibrio harveyi-mediated death of marine gastropods. Environ Microbiol 12(1):12433.DOI: 10.1111/j.1462-2920.2009.02052.x.

14. Garren M, Azam F. 2012. Corals shed bacteria as a potential mechanism of resilience to organic matter enrichment. ISME $J$ 6(6):1159-65. DOI: 10.1038/ismej.2011.180.

15. Garren M, Son K, Raina JB, Rusconi R, Menolascina F, Shapiro OH, Tout J, Bourne DG, Seymour JR, Stocker R. 2013. A bacterial pathogen uses dimethylsulfoniopropionate as a cue to target heat-stressed corals. ISME J [Epub ahead of print]. DOI: 10.1038/ismej.2013.210.

16. Gregoracci GB, Nascimento JR, Cabral AS, Paranhos R, Valentin JL, Thompson CC, Thompson FL. 2012. Structuring of bacterioplankton diversity in a large tropical bay. PLoS One 7(2):e31408.DOI: 10.1371/journal.pone.0031408

17. Guindon S, Gascuel O. 2003. A simple, fast, and accurate algorithm to estimate large phylogenies by maximum likelihood. Syst Biol 52: 696-704.DOI: 10.1080/10635150390235520.

18. Guindon S, Dufayard JF, Lefort V, Anisimova M, Hordijk W, Gascuel O. 2010. New algorithms and methods to estimate Maximum-Likelihood phylogenies: assessing the performance of PhyML 3.0. Syst Biol 59: 307-21.

19. Hibbing ME, Fuqua C, Parsek MR, Peterson SB. 2010. Bacterial competition: surviving and thriving in the microbial jungle. Nat Rev Microbiol 8(1):15-25. DOI: 10.1038/nrmicro2259. Review.

20. Hunt DE, David LA, Gevers D, Preheim SP, Alm, EJ, Polz MF. 2008. Resource partitioning and sympatric differentiation among closely related bacterioplankton. Science 320(5879):1081-5.DOI: 10.1126/science.1157890.

21. Letunick I, Bork P. 2007. Interactive Tree Of Life (iTOL): an online tool for phylogenetic tree display and annotation. Bioinformatics 23(1):127-8.DOI: 10.1093/bioinformatics/btl529.

22. Luo P, Jiang H, Wang Y, Su T, Hu C, Ren C, Jiang X. 2012. Prevalence of mobile genetic elements and transposase genes in Vibrio alginolyticus from the southern coastal region of China and their role in horizontal gene transfer. Int Microbiol 15(4):201-10. DOI: 10.2436/20.1501.01.173

23. Martinez-Urtaza J, Huapaya B, Gavilan RG, Blanco-Abad V, Ansede-Bermejo J, Cadarso-Suarez C, Figueiras A, Trinanes J. 2008. Emergence of asiatic Vibrio diseases in South America in phase with El Niño. Epidemiology 19:829837. DOI: 10.1097/EDE.0b013e3181883d43.

24. Materna AC, Friedman J, Bauer C, David C, Chen S, Huang IB, Gillens A, ClarkeMcLaughlin JB, DePaola A, Bopp CA, Martinek KA, Napolilli NP, Allison CG, Murray SL, Thompson EC, Bird MM, Middaugh JP. 2005. Outbreak of Vibrio parahaemolyticus gastroenteritis associated with Alaskan oysters. New Eng J Med 353:1463-1470. DOI: 10.1056/NEJMoa051594. 
563

564

565

566

567

568

569

570

571

572

573

574

575

576

577

578

579

580

581

582

583

584

585

586

587

588

589

590

591

592

593

594

595

596

597

598

599

600

601

602

603

604

605

606

25. McCarter L. 1999. The multiple identities of Vibrio parahaemolyticus. Journal of Molecular Microbiology and Biotechnology 1:51-57

26. McDougald D, Kjelleberg S. 2006. Adaptive responses of Vibrios. In: Thompson FL, Austin B, Swings J (eds) The biology of Vibrios. American Society for Microbiology, Washington D.C., p 133-155

27. Ministério do Meio Ambiente - MMA. Programa REVIZEE: avaliação do potencial sustentável de recursos vivos na zona econômica exclusiva: relatório executivo. 2006. Brasília, Brasil. 280 p. ISBN: 85-7738-027-0.

28. Moreira APB, Chimetto Tonon LA, Valle P, Pereira C, Alves N, Amado-Filho G M, Francini-Filho RB, Paranhos R, Thompson FL. 2013. Culturable Heterotrophic Bacteria Associated with Healthy and Bleached Scleractinian Madracis decactis and the Fireworm Hermodice carunculata from the Remote St. Peter and St. Paul Archipelago, Brazil. Current Microbiology 68(1):38-46. DOI: 10.1007/s00284-013-0435-1.

29. Moreira AP, Duytschaever G, Tonon LAC, Dias GM, Mesquita M, Cnockaert M, Francini-Filho RB, DeVos P, Thompson CC, Thompson FL. 2014. Vibrio madracius sp. nov. isolated from Madracis decactis (Scleractinia) in St Peter \& St Paul Archipelago, Mid-Atlantic Ridge, Brazil. Curr Microbiol 69(4):405-11. DOI: 10.1007/s00284-014-0600-1.

30. Oliveira OMP, Marques AC. 2007. Dinâmica sazonal das massas de água no canal de São Sebastião (SE Brasil) de março de 2005 a maio de 2006. XII Congresso Latino-Americano de Ciências do Mar - XII COLACMAR

31.Paz S, Bisharat N, Paz E, Kidar O, Cohen D. 2007. Climate change and the emergence of Vibrio vulnificus disease in Israel. Environ Res 103:390-396. DOI: 10.1016/j.envres.2006.07.002

32. Pitcher DG, Saunders NA, Owen RJ. 1989. Rapid Extraction of Bacterial Genomic DNA with Guanidium Thiocyanate. Letters in Applied Microbiology 8:151-156. DOI: 10.1111/j.1472-765X.1989.tb00262.x

33. Preheim SP. 2010. Ecology and population structure of Vibrionaceae in the coastal ocean. MIT thesis.

34. Preheim SP, Boucher Y, Wildschutte H, David LA, Veneziano D, Alm EJ, Polz MF. 2011. Metapopulation structure of Vibrionaceae among coastal marine invertebrates. Environ Microbiol 13(1):265-75. DOI: 10.1111/j.14622920.2010.02328.x

35. Reshef L, Ron E, Rosenberg E. 2008. Genome analysis of the coral bleaching pathogen Vibrio shiloi. Arch Microbiol 190(2):185-94. DOI: 10.1007/s00203-0080388-0.

36. Rosenberg E, Koren O, Reshef L, Efrony R, Zilber-Rosenberg I. 2007. The role of microorganisms in coral health, disease e evolution. Nat Rev Microbiol 5: 355-362.DOI: 10.1038/nrmicro1635.

37. Ruwandeepika HA, Defoirdt T, Bhowmick PP, Shekar M, Bossier P, Karunasagar I. 2010. Presence of typical and atypical virulence genes in vibrio isolates belonging to the Harveyi clade. J Appl Microbiol 109(3):888-99. DOI: 10.1111/j.1365-2672.2010.04715.x. 
38. Ruwandeepika HA, Defoirdt T, Bhowmick PP, Karunasagar I, Karunasagar I, Bossier P. 2011. In vitro and in vivo expression of virulence genes in Vibrio isolates belonging to the Harveyi clade in relation to their virulence towards gnotobiotic brine shrimp (Artemia franciscana). Environ Microbiol 13(2):506-17. DOI: 10.1111/j.1462-2920.2010.02354.x.

39. Materna AC, Friedman J, Bauer C, David C, Chen S, Huang IB, Gillens A, Clarke SA, Polz MF, Alm EJ. 2012. Shape and evolution of the fundamental niche in marine Vibrio. ISME J 6(12):2168-77. DOI: 10.1038/ismej.2012.65.

40. Sawabe T, Kita-Tsukamoto K, Thompson FL. 2007. Inferring the evolutionary history of vibrios by means of multilocus sequence analysis. J Bacteriol 189: 7932-7936. DOI:10.1128/JB.00693-07.

41. Sawabe T, Ogura Y, Matsumura Y, Feng G, Amin AR, Mino S, Nakagawa S, Sawabe T, Kumar R, Fukui Y. 2013. Updating the Vibrio clades defined by multilocus sequence phylogeny: proposal of eight new clades, and the description of Vibrio tritonius sp. nov. Front Microbiol 4:414. DOI: 10.3389/fmicb.2013.00414.

42. Sussman M, Loya Y, Fine M, Rosenberg E. 2003. The marine fireworm Hermodice carunculata is a winter reservoir and spring-summer vector for the coral-bleaching pathogen Vibrio shiloi. Environ Microbiol 5(4):250-5. DOI: 10.1046/j.1462-2920.2003.00424.x

43. Szabo G, Preheim SP, Kauffman KM, David LA, Shapiro J, Alm EJ, Polz MF. 2013. Reproducibility of Vibrionaceae population structure in coastal bacterioplankton. ISME J 7(3):509-19. DOI: 10.1038/ismej.2012.134.

44. Tamura K, Peterson D, Peterson N, Stecher G, Nei M, Kumar S. 2011. MEGA5: molecular evolutionary genetics analysis using maximum likelihood, evolutionary distance and maximum parsimony methods. Mol Biol Evol 28(10):2731-9. DOI:10.1093/molbev/msr121.

45. Thompson FL, Gevers D, Thompson CC, Dawyndt P, Naser S, Hoste B, Munn CB, Swings J. 2005. Phylogeny and molecular identification of vibrios on the basis of multilocus sequence analysis. Appl Environ Microbiol 71(9):510715.DOI: 10.1016/j.syapm.2011.09.001.

46. Thompson FL, Gomez-Gil B, Vasconcelos AT, Sawabe T. 2007. Multilocus sequence analysis reveals that Vibrio harveyi and V. campbellii are distinct species. Appl Environ Microbiol 73: 4279-85. DOI: 10.1128/AEM.00020-07

47. Thompson JR, Polz MF. 2006. Dynamics of Vibrio populations and their role in environmental nutrient cycling. In: Thompson FL, Austin B, Swings J (eds) The biology of Vibrios. American Society for Microbiology, Washington D.C., p 190 203

48. Thompson JR, Pacocha S, Pharino C, Klepac-Ceraj V, Hunt DE, Benoit J, Sarma-Rupavtarm R, Distel DL, Polz MF. 2005. Genotypic diversity within a natural coastal bacterioplankton population. Science 307(5713):1311-3. DOI:10.1126/science.1106028.

49. Tilman D. 1982. Resource competition and community structure. Princetown University Press, Princetown. 
650

651

652

653

654

655

656

657

658

659

660

661

662

663

664

665

666

667

668

50. Toren A, Landau L, Kushmaro A, Loya Y, Rosenberg E. 1998. Effect of temperature on adhesion of Vibrio strain AK-1 to Oculina patagonica and on coral bleaching. Appl Environ Microbiol 64:1379-1384.

51. Vezzulli L, Previati M, Pruzzo C, Marchese A, Bourne DG, Cerrano C, VibrioSea Consortium. 2010. Vibrio infections triggering mass mortality events in a warming Mediterranean Sea. Environmental Microbiology 12: 2007-2019. DOI: 10.1111/j.1462-2920.2010.02209.x

52. Vezzulli L, Brettar I, Pezzati E, Reid PC, Colwell RR, Höfle MG, Pruzzo C. 2012. Long-term effects of ocean warming on the prokaryotic community: evidence from the vibrios. ISME J 6(1):21-30. DOI: 10.1038/ismej.2011.89.

53. Wiedenbeck J, Cohan FM. 2011. Origins of bacterial diversity through horizontal genetic transfer and adaptation to new ecological niches. FEMS Microbiol Rev 35(5):957-76. DOI: 10.1111/j.1574-6976.2011.00292.x. Review.

54. Viégas FB, Wattenberg M, Ham FV, Kriss J, McKeon M. 2007. Many Eyes: A Site for Visualization at Internet Scale. Infovis 13(6): 1121-1128. DOI: 10.1109/TVCG.2007.70577

55. Winn KM, Bourne DG, Mitchell JG. 2013. Vibrio coralliilyticus search patterns across an oxygen gradient. PLoS One 8(7):e67975. DOI: 10.1371/journal.pone.0067975. 
669 Figures Legend.

670 Figure 1. Map of Brazil with sampling regions depicted. Microenvironments are 671 highlighted in each sampling site. $A=$ Saint Peter and Saint Paul Archipelago. Hosts 672 investigated Hermodice Carunculata, Scolymia wellsi and Madracis decactis. B= 673 Abrolhos Bank. Sediment, rhodolith, water, Mussismilia brasiliensis, M. hispida and 674 Phylogorgia dilatata. $\mathrm{C}=$ Saint Sebastian region. M. hispida, Zoanthus solanderi, 675 Palythoa caribaeorum and P. variabilis.

676 Figure 2. Inferred habitat associations for all ancestors of sequenced Vibrio strains. The 677 rings surrounding the tree represent the isolation source (outer) and the sampling site 678 (inner) from which strains were isolated. The maximum likelihood assignment of nodes 679 to habitats is shown for clades supported by bootstraps $>80 \%$. Colored circles on each 680 branch indicate the habitat spectrum assignment $(\mathrm{H} 1-\mathrm{H} 8)$ for the node immediately 681 below that branch (see above legend for color scheme). Branch lengths are adjusted to 682 aid visualization and do not represent evolutionary distances. ${ }^{*}$ Highlights the isolation 683 source water.

684 Figure 3. Distribution of the environmental categories that compose each of the 8 685 habitats predicted by AdapML. Distributions are normalized by the total number of 686 isolates in each environmental category to reduce the effect of uneven sampling. 
687 Table 1.Detection of vibrios species found in seawater and at the same time in other 688 hosts investigated in this study. ND = Not detected

\section{Supplementary Material}

690 Supplementary Figure S1. Distribution of the studied regions [Saint Peter and Saint 691 Paul Archipelago (SPSPA), Abrolhos Bank (AB) and Saint Sebastian channel (SS)] in 692 each habitat composition defined by AdaptML approach. Scale represents percentage.

693 Supplementary Figure S2. Vibrio species diversity in the habitats. The figure shows 694 how the 775 Vibrio strains are distributed in each habitat. The side of the circle 695 represents the proportion of total strains in each group. Others $=$ represents Vibrio 696 species with low abundance found in that group. Figure generated through Many Eyes 697 website (Viegas et al., 2007).

698 Supplementary Figure S3. PyrH tree of vibrios from plankton, rhodoliths and 699 corals. Phylogenetic tree based on the neighbor-joining method using $\mathrm{pyrH}$ gene 700 sequences showing the relationships among representative Vibrio species from plankton 701 (blue color), rhodoliths (red color) and corals (black). Type strains of Vibrio were 702 included (bold black). Distance estimations were obtained according to the Kimura-2703 parameter model. Bootstrap percentages after 1000 replications are shown. Divergence 704 bar estimated at $2 \%$. Depth is indicated for planktonic strains.

705 Supplementary Figure S4. Evolutionary history inferred by using the Neighbor-Joining 706 method based on 532 positions of $\mathrm{pyrH}$ gene sequence in the final dataset. The 707 bootstrap test (1000 replicates) are shown next to the branches. The evolutionary 
708 distances were computed using the Maximum Composite Likelihood method and are in

709 the units of the number of base substitutions per site. The analysis involved 316

710 nucleotide sequences including only strains from $A B$ region and type strains of each

711 represented species. All ambiguous positions were removed for each sequence pair.

712 White and red circles represent strains from benthic source and blue circles from 713 pelagic.

714 Supplementary Figure S5. Inferred habitat associations for all ancestors of sequenced 715 Vibrio strains from $A B$ region. The rings surrounding the tree represent the isolation 716 source (outer) and the collection point (inner) from which strains were isolated. The 717 maximum likelihood assignment of nodes to habitats is shown for The maximum

718 likelihood assignment of nodes to habitats is shown for clades supported by bootstraps $719>80 \%$.. Colored circles on each branch indicate the habitat assignment $(\mathrm{H} 1-\mathrm{H} 6)$. Branch 720 lengths were adjusted to aid visualization and do not represent evolutionary distances.

721 Supplementary Figure S6. Habitat distribution according to sampling time. The values 722 represents percentages.

723 Supplementary Table S1. Strain list.

724 Supplementary Table S2. Habitat assignment. 


\section{1}

Brazil Map showing the sampling regions

Microenvironments are highlighted in each sampling site. $A=$ Saint Peter and Saint Paul Archipelago. Hosts investigated Hermodice Carunculata, Scolymia wellsi and Madracis decactis. $\mathrm{B}=$ Abrolhos Bank. Sediment, rhodolith, water, Mussismilia brasiliensis, M. hispida and Phylogorgia dilatata. $\mathrm{C}=$ Saint Sebastian region. M. hispida, Zoanthus solanderi, Palythoa caribaeorum and $P$. variabilis.

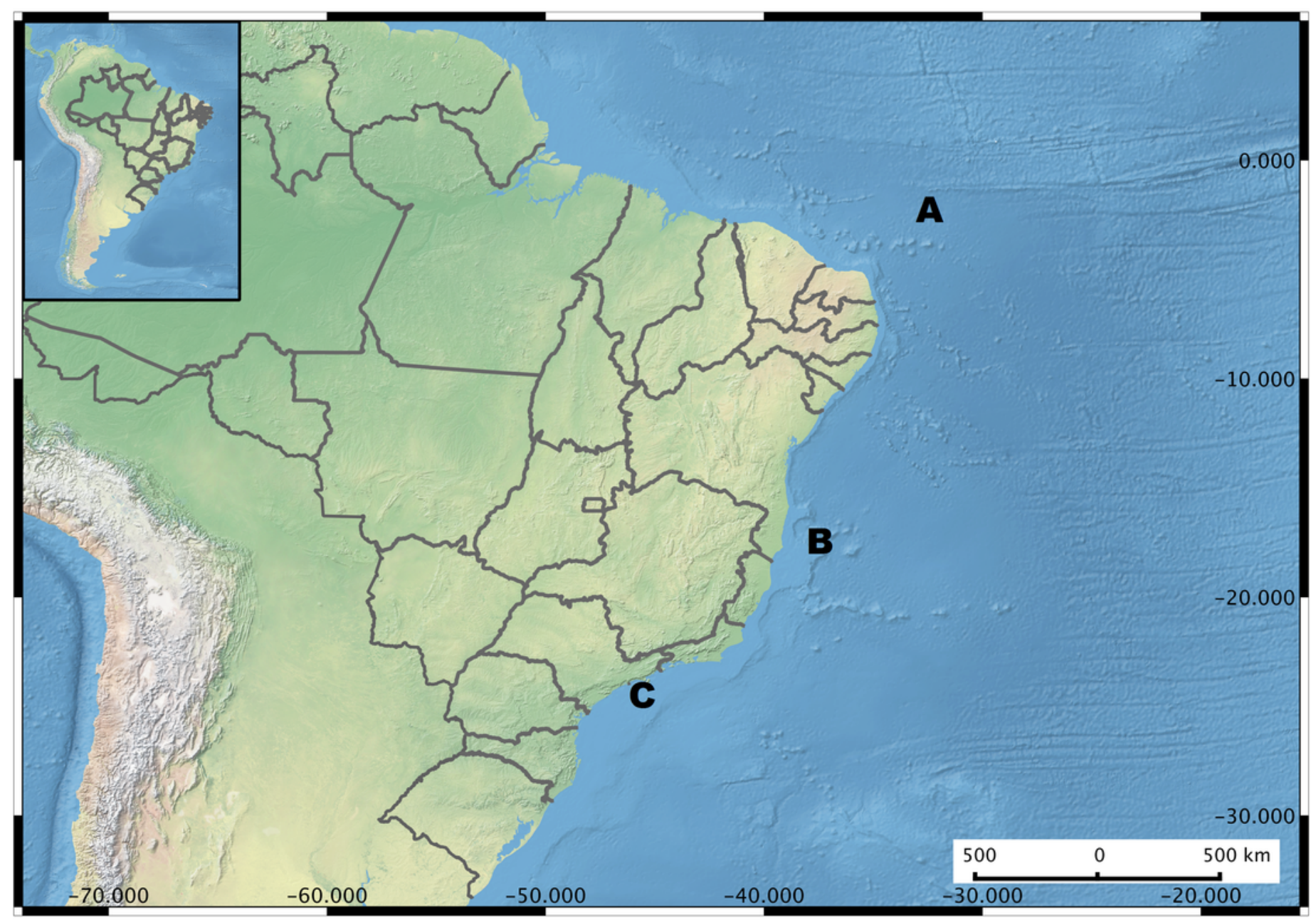


Inferred habitat associations for all ancestors of sequenced Vibrio strains.

The rings surrounding the tree represent the isolation source (outer) and the sampling site (inner) from which strains were isolated. The maximum likelihood assignment of nodes to habitats is shown for all nodes, regardless of the confidence of each prediction. Colored circles on each branch indicate the habitat spectrum assignment (H1-H8) for the node immediately below that branch (see above legend for color scheme). Branch lengths are adjusted to aid visualization and do not represent evolutionary distances.* Highlights the isolation source water.
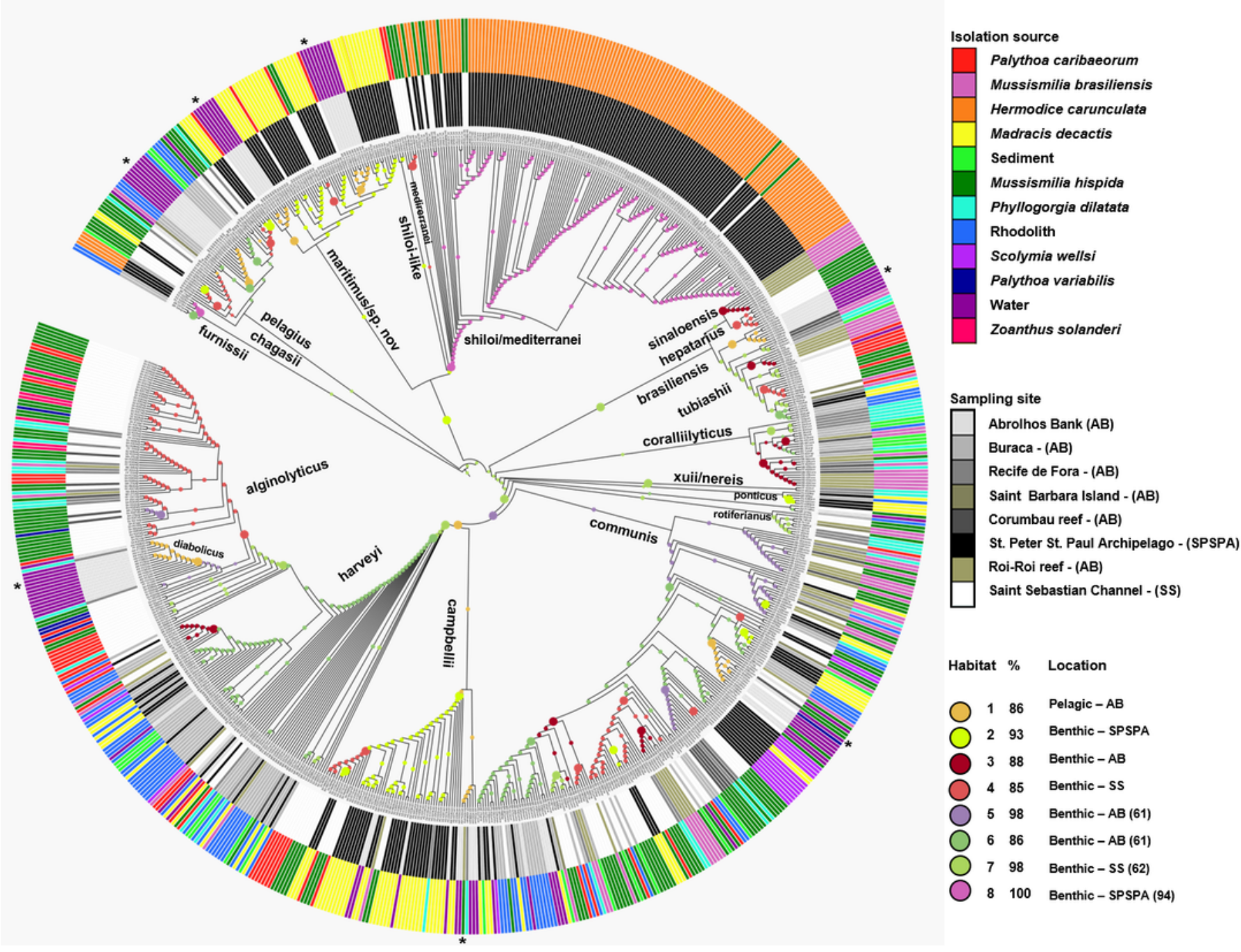


\section{3}

Distribution of the environmental categories that compose each of the 8 habitats predicted by AdapML.

Distributions are normalized by the total number of isolates in each environmental category to reduce the effect of uneven sampling.

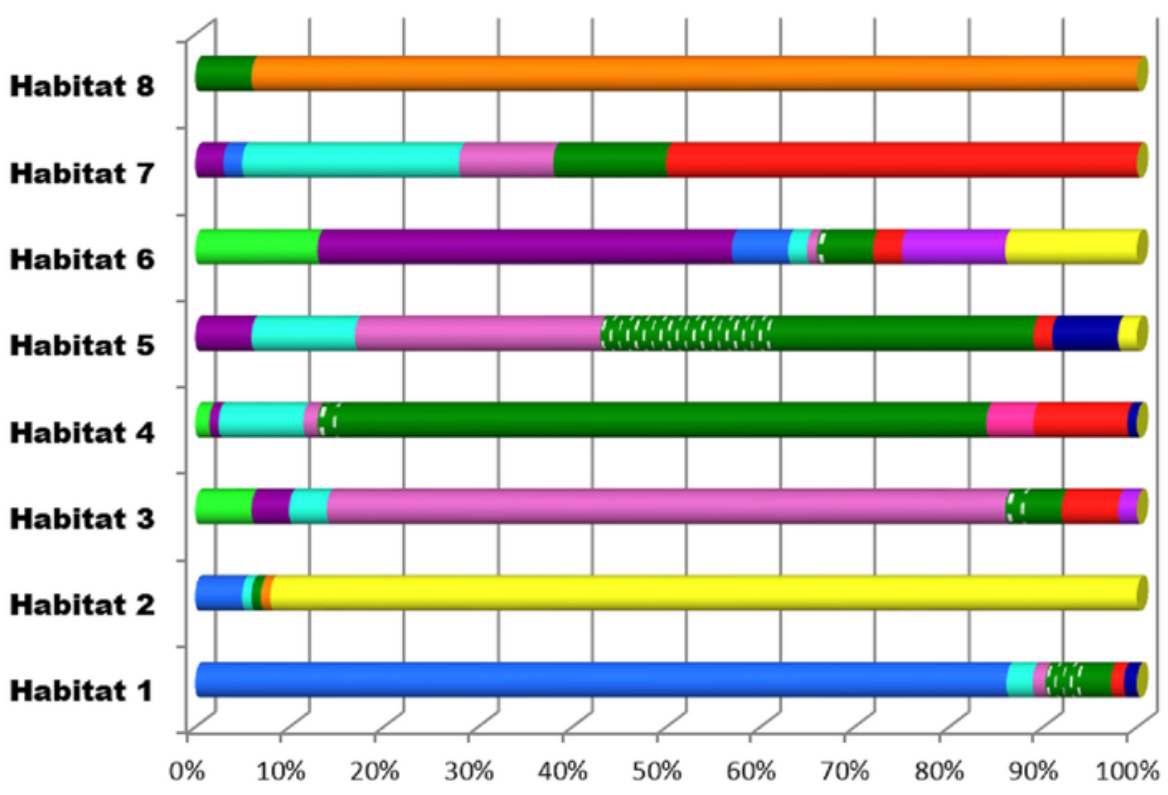

Isolation source

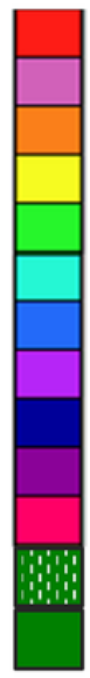

Palythoa caribaeorum (SS)

Mussismilia brasiliensis (AB)

Hermodice carunculata (SPSPA)

Madracis decactis (SPSPA)

Sediment (AB - Buracas)

Phyllogorgia dilatata (AB)

Water (AB)

Scolymia wellsi (SPSPA)

Palythoa variabilis (SS)

Rhodolith (AB - Buracas)

Zoanthus solanderi (SS)

Mussismilia hispida (AB)

Mussismilia hispida (SS) 


\section{Table $\mathbf{1}$ (on next page)}

Detection of vibrios species found in seawater and at the same time in other hosts investigated in this study.

$\mathrm{ND}=$ Not detected 
Table 1.Detection of vibrios species found in seawater and at the same time in other hosts investigated in this study. ND = Not detected

\begin{tabular}{|c|c|c|c|c|c|c|c|c|c|}
\hline & M.hispida & P.dilatada & $\begin{array}{l}\text { M.decacti } \\
s\end{array}$ & $\begin{array}{l}\text { M.brasiliensi } \\
s\end{array}$ & P.caribaeorum & S. wellsi & rhodolith & P.variabilis & sediment \\
\hline $\begin{array}{l}\text { V.communi } \\
s\end{array}$ & $x$ & $x$ & $x$ & $x$ & $x$ & $x$ & $x$ & $x$ & ND \\
\hline V.harveyi & $x$ & $x$ & $x$ & $x$ & $x$ & $x$ & $x$ & ND & $x$ \\
\hline V.campbellii & $x$ & $x$ & $x$ & $x$ & $x$ & ND & ND & ND & ND \\
\hline V.chagasii & $x$ & $x$ & $x$ & $x$ & ND & ND & ND & ND & $x$ \\
\hline V.pelagius & $x$ & $x$ & $x$ & ND & ND & ND & ND & ND & ND \\
\hline V.diabolicus & $x$ & $x$ & ND & ND & ND & ND & ND & ND & ND \\
\hline
\end{tabular}

